\title{
Sampling and sampling methods
}

\begin{abstract}
This article is on representation of basis and the basis selection of techniques. The representation of this two is performed either by the method of probability random sampling or by the method of non-probability random sampling. The selection of random type is done by probability random sampling while the non-selection type is by non-probability probability random sampling. This selection of techniques is talking about either without control (unrestricted) or with control (restricted) when individually the element of each sample is selected from a given totality, the drawn of sample element goes with unrestricted while all the other types of the sampling is to be considered as a restricted sampling.
\end{abstract}

Volume 5 Issue 6 - 2017

\author{
Ilker Etikan, Kabiru Bala \\ Near East University Faculty of Medicine Department of \\ Biostatistics, Cyprus
}

Correspondence: Ilker Etikan, Near East University Faculty of Medicine Department of Biostatistics, Nicosia-TRNC, Cyprus, Email ietikan@gmail.com

Received: April 08, 2017 | Published: May 4, 2017

\section{Introduction}

The aim of this article is to discuss about the sampling and sampling technicality. Statistical agencies prefer the probability random sampling. In business, companies, marketers mostly relay on non-probability sampling for their research, the researcher prefers that because of getting confidence cooperation from his respondent especially in the business sample survey like consumer price index. In New Zealand the proficient set on consumer price index committee advice the government on the their CPI.

\section{Non-probability sampling}

Non-probability sampling is a sampling procedure that will not bid a basis for any opinion of probability that elements in the universe will have a chance to be included in the study sample. We are going to see from diverse method of five different sampling considering the nonrandom designs. which are; Quota sampling, Accidental sampling, Judgemental sampling or Purposive sampling, Expert sampling, Snowball sampling, Modal instant sampling .From the listed the researcher has to deliberately select items to be sample. This type of sampling is costly in application.

\section{Types of non-probability random sampling}

\section{Quota sampling}

The researcher here is ease of access to his sample population by using quota sample, his tallying will be at his convenience guide by some evident of characteristic, such as sex, race, based on population of interest. The sample selection is by the convenient door of the researcher, Any person or individual mistakenly seen with the same characteristics will be asked pertaining the subject of the research for inclusion. It will flow in the same manner until the desired number is achieved. Quota sampling is of two types; first proportionate quota sampling represent the characteristics of major population by sampling a proportional total. Example if we are interested in studying population of 40 percent of females and 60 percent of males. We need a 100 size for the sample; the selection will not stop unless the target is hit before stopping. Meanwhile when the exact number of either male or female is gotten, say 40 female, the selection for the male has to continue in the same process, eventually when a legitimate female comes across, it will not be selected because there number is already completed.

The major setback of purposive sampling is that you necessity to agree on the specific features of the quota to base on. This will be either to base on religion, age, education gender; etc. The nonproportional quota sampling is a technique with small restriction of minimum of sample number of unit from each category. It's not interested in having a number that will match the proportions of the population. Rather need to have sufficient to guarantee that you will be capable to talk about even a small cluster in the population. The method is a non-probabilistic sampling that typically used in assuring that small groups of samples are adequately represented.

\section{Accidental sampling}

Is convenience in reading the sampling population, mostly used among marketers or newspaper researchers. It has the same advantages and disadvantages as quota sampling and it is not guided by any obvious characteristics.

\section{Judgmental or purposive sampling}

The sampling design is based on the judgement of the researcher as to who will provide the best information to succeed for the objectives study. The person conducting the research need to focus on those people with the same opinion to have the required information and be willing of sharing it.

\section{Expert sampling}

The researcher here seeks for the consent of those that are expert or known expert in the area of study, and begin the process of collecting his information directly from individual or group of respondent. It also involves sample assembling of group of people that can demonstrate using their experience or those that specialised in part of the areas. The reasons for using expert sampling are to have a better way of constructing the views of individuals that are expert in a definite area. It is also used in providing confirmation of validity to another approach of a selection of sampling. 


\section{Snowball sampling}

Is a design process of selection usually done by using, networks. It is useful when the researcher know little about a group or organisation to study; contact with few individuals will direct him to other group. The selection of the study sample will be useful for communication aspect, in making decision or indifussion of knowledge to people. The disadvantage is that the choice of the whole sample balances on the choice of individuals from the beginning of the stage, belonging to a particular clique or have ample biases. It will difficult to use when the sample becomes larger and larger.

\section{Modal instant sampling}

Frequent of cases is sample, in this type of sampling we sample the most frequent cases. It can also be seen as the one with the highest happening of value in a given distribution or the one with most characteristic incident. In a lot of formal public informal public opinion polls, for example, interviewing a typical voter. There are problems with these types of sampling. First off all how are we going to know a model of case or typical case? We can be able to say that a modal voter is could be any individual that has average of age, level of educational background and income in the population. But it will not be clear to use the average considering the skewed distribution of income, for example, and, how would you know that those three from the variables are only relevant event that will classify as representative voter? What if religion and ethnicity background is another factor?

\section{Heterogeneity sampling}

Is can be used if we want to include all the opinions or views and we are not going to consider about representing of these views per head. This sampling is also called sampling of diversity and is almost opposite with the modal instant sampling, the interest is to have a comprehensive variety of ideas, not to identify the modal instance or typical once. We determine that there is a ground of all possible ideas applicable to some topic and that we want to sample the population not the population of those people who have the ideas. What the sample study need is ideas not people.

\section{Sampling}

Probability sampling is also known as 'random sampling this is a sampling which permits every single item from the universe to have an equal chance of presence in the sample. For instance in a raffle draw were individual units will be picked from the overall group not a deliberately nonetheless by certain process, this incident is only a blind of chance that will limits whether unique items or the additional items is to be preferred. Probability sampling type will going to be based on the following; Systematic random sampling, Stratified types of sampling, Cluster sampling, Multi-stage sampling, Area sampling,

\section{Types of probability random sampling}

\section{Systematic sampling}

Thus, in systematic sampling only the first unit is selected randomly and the remaining units of the sample are to be selected by a fixed period, it is not like a random sample in real sense, systematic sampling has confident points of having improvement over the simple random sample, as ample the systematic sample is feast more equally completed to the complete population. The execution of the method is very easy, less in cost and conveniently to use in case of a larger population.

\section{Stratified sampling}

Is applied when population from which sample to be drawn from the group does not have homogeneous group of stratified sampling technique, in generally it is used to obtain a representative of a good sample. Stratified type of sampling divide the universe into several sub group of population that are individually more homogeneous than the total population (the sub-populations differences are called strata) and select items will be selected from each stratum to generate a sample in this case each of the stratum will be more homogeneous with the population, more precise estimate will be generated from each for stratum. We get the estimate of the population from each stratum when there is better accuracy from each of the component; we get a better estimate of the whole. The stratified sampling gives more reliable and detailed information about the sample. The forming of strata is informed of purposive system from a well experience and special judgment of a researcher. The strata are defined by the population characteristics of the estimate. The fitted organized design for stratification is the pilot study, which assists in the determination of more appropriate and efficient planning for stratification and element within both of the stratum are homogeneous while element between each strata is heterogeneous. Items selection from each separately stratum is done by using simple random sampling and systematic random sampling because they are reflected more proper in a convinced situations. Proportional allocation is used when the sample size from different stratum will be kept proportional to the strata size. To compare the difference for the strata, selecting equal sample from each of the stratum would be more efficient even though the strata will be different in sizes.

In cases the strata differs not only by size but also in variability and it is considered reasonable to take larger samples from the more variable of strata and smaller samples from the less variable strata and account for both differences of stratum size and differences of stratum variability. Disproportionate sampling design is required in the sample sizes of $k$ strata which is called the optimum allocation.

\section{Cluster sampling}

When the total area of the research is too large a better way for the researcher is to divide the area in to smaller part of the same or equal and then select randomly from the smaller units. it is expected that that the total population is to be divided in to relatively a smaller number which are still from the clusters of smaller units and then some of this cluster unit will be selected randomly so that it will be included in the general sampling.

One of the advantages of using the cluster sampling is economical in reducing cost by concentrating on the selected clusters it gives less precision than the simple random sampling.

\section{Multi-stage sampling}

Is an additional progress of the belief that cluster sampling have. Normally in multi-stage sampling design is applicable in a big inquires of geographical area, for the entire country. Multistage sampling has to with the combination of the various methods of probability sampling in most effective and efficient approach.

\section{Area sampling}

Is a design sampling that deals with subdivision of environment that represents clusters of unit's that centred on terrestrial location. 


\section{Conclusion}

In conclusion the probability random sampling is more preferable because the researcher generate his data for the use of entire population by using probabilistic method to control biased during the sampling, based on evidence generated by the agencies of statistical official that the non-probability techniques is based on purpose that lead to assumption which resulting to risk. Basing on assumption means one will generate inappropriate generalization of the population. ${ }^{1-20}$

\section{Acknowledgement}

None.

\section{Conflict of interest}

None.

\section{References}

1. Lavrakas PJ. Non probability sampling Encyclopaedia of survey research methods; 2008

2. CR Kothari. Research Methodology Methods andTechniques. 2nd ed. revised edition, New age international publishers; 1995. p. 55-67.

3. Charles T, Fen Y. Mix methods sampling: A typology with examples. Journal of mixed methods research. 2007. p. 77-100.

4. Dohert M. Probability versus non-probabilty sampling in sample surveys. The New Zealand statistical review. 1994. p. 21-28.

5. Sue, Greenes. Business Research Book. 2008. p. 47-50.

6. Etikan I, Musa SA, Alkassim RS. Comparison of covenience sampling and purposive sampling. American Journal of theoretical and applied statistics. 2016. p. 1-4.

7. Helen D. The journal of Educational Research. 1993. p. 133-136.
8. Henry GT. Practical sampling, New Bury Park. CA Sage. 1990.

9. Etikan I, Alkassim R, Abubakar S. Comparision of Snowball Sampling and Sequential Sampling Technique. Biom Biostat Int J. 2016;3(1):00055.

10. Irnelda $T$, Coyne B. samplimng in qualitative research. purposeful and theoritical sampling; merging or clear boundaries. $J A d v$ Nurs. 1997;26(3):23-630.

11. Johnson RB, Onwuegbuzie. Mixed methods research; a research paradigm whose time has come. Educational researcher. 2004.

12. Jonhstone L, Keith S. Sampling hard to reach population with respondent dreven sampling methodological inovation online. 2010.

13. Feild L, Pruchno RA, Bewley J, et al. Using probaility vs. Noprobability samplig to hard to acces participants for health related research: costs and contrasts. J Aging Health. 2006;18(4):565-583.

14. Mason J. Qualitative researching. 2nd ed. London. 2002.

15. Miller PG, Johnston J, Dunn M, et al. Comparing probability \& non probability sampling methods in Ecstacy Research: Implications for the the internet as a research tools. Subst Use Misuse. 2010;45(3):437-450.

16. Ranjit, Kumar. Research Methodology step by step guide for beginners. 3rd ed. 2011. p. 175-194.

17. Salehi MM and Seber GAF. A general inverse. Sampling scheme and its application to. Adaptive cluster. Australian \& New Zealand Journal of Statistics. 2004;46(3):483-494.

18. Smith T. On the validity of inference from non random samples. Journal of the royal statistics society. 1983;146:394-403.

19. Strauss A, Cobin J. Basic of qualitative research grounded theory, procedures and techniques. 1990.

20. Stephen F, McCarthy P. Sampling opinions;John Wiley and Sons, New York, USA; 1958 